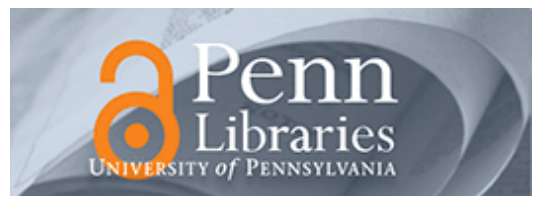

University of Pennsylvania ScholarlyCommons

$1-1-2004$

\title{
The Continua of Biliteracy and the Bilingual Educator: Educational Linguistics in Practice
}

Nancy H. Hornberger

University of Pennsylvania, nancyh@gse.upenn.edu

Follow this and additional works at: https://repository.upenn.edu/gse_pubs

Part of the Bilingual, Multilingual, and Multicultural Education Commons

\section{Recommended Citation}

Hornberger, N. H. (2004). The Continua of Biliteracy and the Bilingual Educator: Educational Linguistics in Practice. Retrieved from https://repository.upenn.edu/gse_pubs/9

Copyright Multilingual Matters. Reprinted from International Journal of Bilingual Education and Bilingualism, Volume 7, Issues 2\&3, pages 155-171.

This paper is posted at ScholarlyCommons. https://repository.upenn.edu/gse_pubs/9

For more information, please contact repository@pobox.upenn.edu. 


\title{
The Continua of Biliteracy and the Bilingual Educator: Educational Linguistics in Practice
}

\author{
Abstract \\ The continua model of biliteracy offers a framework in which to situate research, teaching, and language \\ planning in linguistically diverse settings; bilingual teacher education represents a conjunction of all three \\ of these and hence, a good candidate for applying the continua model. This paper uses selected \\ experiences in language teacher education as practised at the University of Pennsylvania Graduate \\ School of Education to illustrate the potential of the continua model as heuristic in continually (re)writing \\ the bilingual or language educator's knowledge base in response to the demands of educational policy \\ and practice. A series of vignettes serves as a means for exploring dilemmas confronting bilingual (and \\ language) educators and ways in which the continua model might shape a response: the global/local \\ dilemma - global social, cultural, and political trends as contexts for biliteracy; the standard/nonstandard \\ dilemma - media of biliteracy as reflected in evolving views of language and literacy in the world; the \\ language/content dilemma - enquirybased teacher education as an approach to the development of \\ biliteracy; and the language/culture/identity dilemma - teachers' and learners' identities and cultures as \\ they relate to biliteracy content. The paper concludes with a few comments on bilingual educators as \\ researchers, teachers, and language planners and on the need, now more than ever, for bilingual \\ educators to be advocates.
}

\section{Keywords}

language and identity, language and content, global english, language planning, language teacher education, nonstandard languages in education

\section{Disciplines}

Bilingual, Multilingual, and Multicultural Education

\section{Comments}

Copyright Multilingual Matters. Reprinted from International Journal of Bilingual Education and Bilingualism, Volume 7, Issues 2\&3, pages 155-171. 


\title{
The Continua of Biliteracy and the Bilingual Educator: Educational Linguistics in Practice'
}

\author{
Nancy $H$. Hornberger \\ Graduate School of Education, University of Pennsylvania
}

The continua model of biliteracy offers a framework in which to situate research, teaching, and language planning in linguistically diverse settings; bilingual teacher education represents a conjunction of all three of these and hence, a good candidate for applying the continua model. This paper uses selected experiences in language teacher education as practised at the University of Pennsylvania Graduate School of Education to illustrate the potential of the continua model as heuristic in continually (re)writing the bilingual or language educator's knowledge base in response to the demands of educational policy and practice. A series of vignettes serves as a means for exploring dilemmas confronting bilingual (and language) educators and ways in which the continua model might shape a response: the global/local dilemma global social, cultural, and political trends as contexts for biliteracy; the standard/nonstandard dilemma - media of biliteracy as reflected in evolving views of language and literacy in the world; the language/content dilemma - enquirybased teacher education as an approach to the development of biliteracy; and the language/culture/identity dilemma - teachers' and learners' identities and cultures as they relate to biliteracy content. The paper concludes with a few comments on bilingual educators as researchers, teachers, and language planners and on the need, now more than ever, for bilingual educators to be advocates.

Keywords: language and identity, language and content, global English, language planning, language teacher education, nonstandard languages in education

\section{Introduction}

The continua model of biliteracy offers a framework in which to situate research, teaching, and language planning in linguistically diverse settings; bilingual teacher education represents a conjunction of all three of these and hence, a good candidate for applying the continua model. In what follows, I use selected experiences in language teacher education as practised at the University of Pennsylvania's Graduate School of Education (PennGSE) to illustrate the potential of the continua model as heuristic in continually (re)writing the bilingual or language educator's knowledge base in response to the demands of policy and practice in today's ever-evolving schools, in the US and worldwide.

After a brief introductory overview of the continua model and of the Educational Linguistics programmes at PennGSE, we will take up a series of vignettes as a means for exploring some of the dilemmas confronting bilingual (and language) educators in today's postmodern and increasingly multicultural and globalised world; and suggest ways in which the continua model might shape a response. We begin by looking at some recent global social, 
cultural, and political trends, as contexts for biliteracy (the global/local dilemma); and then take up the media of biliteracy as reflected in evolving views of language and literacy in that world (the standard/nonstandard dilemma). Thereafter, we will turn to enquiry-based teacher education as an approach to the development of biliteracy (the language/content dilemma); and finally to teachers' and learners' identities and cultures as they relate to biliteracy content (the language/culture/identity dilemma). I conclude with a few comments on bilingual educators as researchers, teachers, and language planners and on the need, now more than ever, for bilingual educators to be advocates.

\section{Continua of Biliteracy ${ }^{2}$}

The continua model of biliteracy uses the notion of intersecting and nested continua to demonstrate the multiple and complex interrelationships between bilingualism and literacy and the importance of the contexts, media, and content through which biliteracy develops. Biliteracy, in this model, refers to 'any and all instances in which communication occurs in two (or more) languages in or around writing' (Hornberger, 1990: 213); and the notion of continuum is intended to convey that although one can identify (and name) points on the continuum, those points are not finite, static, or discrete. There are infinitely many points on the continuum; any single point is inevitably and inextricably related to all other points; and all the points have more in common than otherwise with each other.

The purpose of using the continuum as the basic building block of the model is to break down the binary oppositions so characteristic of the fields of bilingualism and literacy and instead draw attention to the continuity of experiences, skills, practices, and knowledge stretching from one end of any particular continuum to the other. Specifically, the continua model depicts the development of biliteracy along intersecting first language-second language, receptive-productive, and oral-written language skills continua; through the medium of two (or more) languages and literacies whose linguistic structures vary from similar to dissimilar, whose scripts range from convergent to divergent, and to which the developing biliterate individual's exposure varies from simultaneous to successive; in contexts that encompass micro to macro levels and are characterised by varying mixes along the monolingual-bilingual and oral-literate continua; and with content that ranges from majority to minority perspectives and experiences, literary to vernacular styles and genres, and decontextualised to contextualised language texts (Hornberger, 1989; Hornberger \& Skilton-Sylvester, 2000).

Figures 1 and 2 schematically represent the framework by depicting both the nested and intersecting nature of the continua, while Figure 3 summarises all 12 continua (four nested sets of three intersecting continua each). It is worth noting that Figures 1 and 2 are not intended to represent the continua model per se, but are meant rather as aids to visualisation of the relationships among the continua. Figure 1 depicts the continua as a series of nested boxes representing contexts, media, content, and development of biliteracy respectively, while Figure 2 shows that each box is a cluster of its three intersecting continua. Not only is the three-dimensionality of any one set of three intersecting 


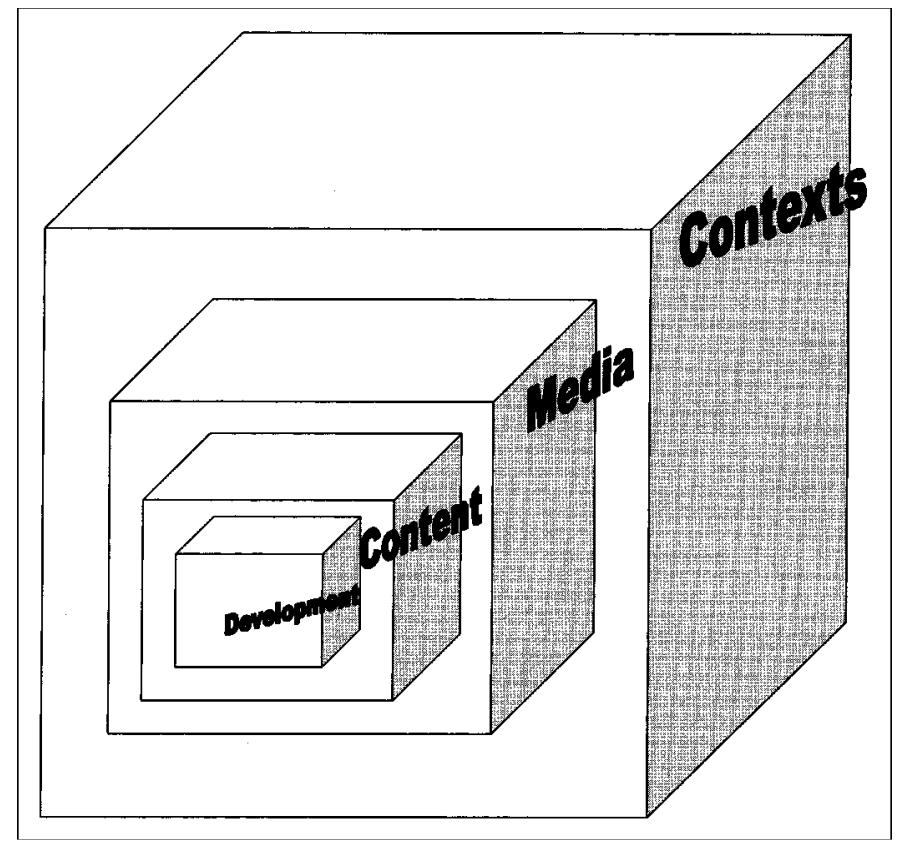

Figure 1 Nested relationships among the continua of biliteracy

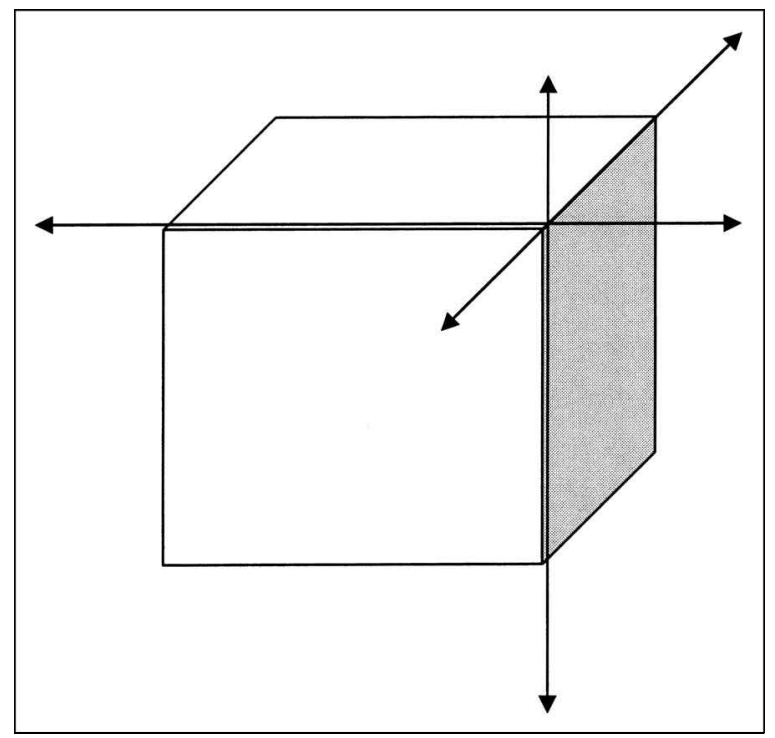

Figure 2 Intersecting relationships among the continua of biliteracy

continua representative of the interrelatedness of those three constituent continua, but it should be emphasised that the interrelationships extend across the four sets of continua as well; hence the nesting of the three-dimensional spaces. Finally, the two-way arrows in Figure 3 represent the infinity and fluidity of movement along each of the continua; the three-dimensional boxes 


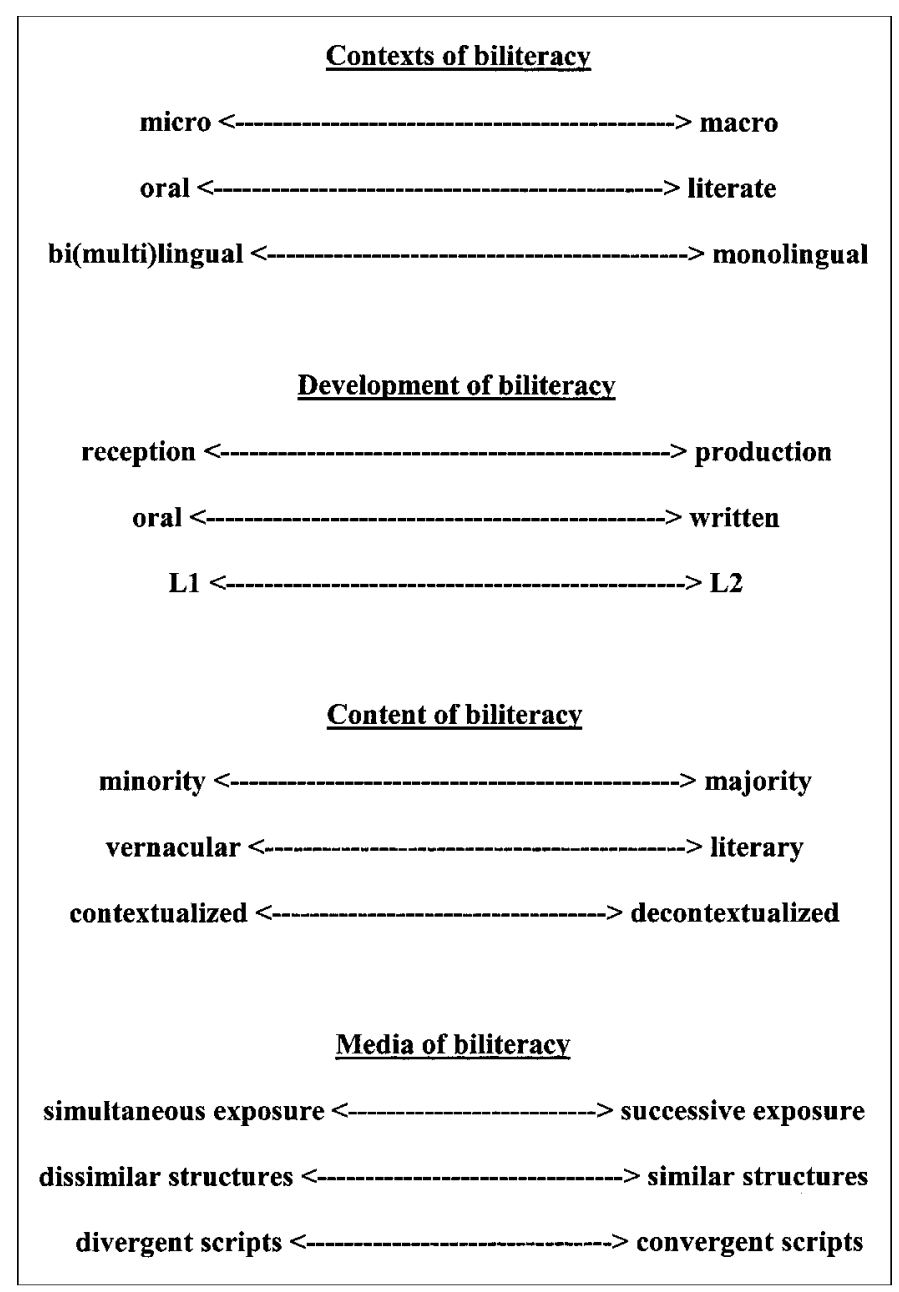

Figure 3 The continua of biliteracy

must also be visualised as infinitely expanding and contracting spaces, not bounded boxes as drawn in Figures 1 and 2 .

The notion of continuum conveys that all points on a particular continuum are interrelated, and the intersecting and nested relationships among the continua convey that all points across the continua are also interrelated. The model suggests that the more their learning contexts and contexts of use allow learners and users to draw from across the whole of each and every continuum, the greater are the chances for their full biliterate development and expression (Hornberger, 1989: 289). Implicit in that suggestion is a recognition that attention has not usually been given to all points and that movement along the continua and across the intersections may well be contested. In educational policy and practice regarding biliteracy, there tends to be an implicit privileging of one end of the continua over the other such that one end of each continuum is associated with more power than the other (e.g. written develop- 
ment over oral development); there is a need to contest the traditional power weighting by paying attention to, granting agency to, and making space for actors and practices at what have traditionally been the less powerful ends of the continua (Hornberger \& Skilton-Sylvester, 2000: 99).

In order to understand any particular instance of biliteracy, be it at the level of individual actor, interaction, event, practice, activity, programme, site, situation, society, or world, we need to take account of all dimensions represented by the continua. At the same time, the advantage of the model is that it allows us to focus for analytical purposes on one or selected continua and their dimensions without ignoring the importance of the others. Here, we will consider bilingual and language teacher education as practised at PennGSE as an instance of biliteracy and focus, for analytical purposes, on each set of three continua - contexts, media, development, and content, consecutively- as illustrated by experiences of bilingual and language educatorsin-the-making in the programme. I borrow and adapt the term bilingual educators-in-the-making from Varghese (2000), who depicted the experiences of several bilingual educators through the course of their professional development workshop and beyond, as they returned to the classroom. We will return to her study below.

\section{Educational Linguistics in Practice}

When, in 1976, a graduate programme in Educational Linguistics was inaugurated at the University of Pennsylvania's Graduate School of Education (PennGSE), two historical 'accidents' conspired to create a context which fostered the development of an integrated, socioculturally/sociolinguistically informed, interdisciplinary, enquiry-based approach to bilingual, English as a Second or Foreign Language (ESL/EFL), and foreign language teacher education, an approach and programmes which endure and thrive to the present. ${ }^{3}$ These accidents were, first, that PennGSE happens to be in a state that neither then nor now offers either bilingual or ESL certification for teachers; and second, that the Dean who inaugurated the programme and oversaw its first several years happened to be one of this century's foremost sociolinguists, anthropological linguist Dell Hymes.

The lack of either ESL or bilingual certification in the Commonwealth of Pennsylvania had many disadvantages for the fields of bilingual education and language education more generally, but one benefit of this absence was that our bilingual and language teacher education programmes had the freedom to evolve in response to research, theory, and practice in the field, without the specialised constraints which might have been imposed by separate sets of certification requirements in bilingual, ESL, and foreign language education. At the same time, Dean Hymes' strong scholarly leadership in sociolinguistic and sociocultural approaches to education provided an academic environment with multiple strengths in language, literacy and culture located not only in Educational Linguistics, but across the school, which infused and influenced the programmes from their very beginnings.

Similarly, the lack of a clearly defined and widely practised field of Educational Linguistics then, as now, confers both benefits and disadvantages in our work. On the one hand, there is the freedom to define the field by our 
practice; on the other, the ambiguity of professional identity is at times experienced as a burden (as testified by students and faculty in the Educational Linguistics programme at a recent Educational Linguistics Forum held at PennGSE, 5 December 2002). This burden of ambiguity is the same paradox which lies at the core of the continua of biliteracy and of the bilingual educators' dilemmas discussed below. It is not my intent to gloss over the very real challenges entailed, but rather to underline that there are freedoms, as well as burdens, in these dilemmas. ${ }^{4}$

Our PennGSE approach to bilingual and language education is one which stresses an inclusive and contextualised view of the communicative competence bilingual and language educators seek to instill in their students, and of the knowledge and practices of bilingual and language educators themselves. We also take an integrated, interdisciplinary approach to language education in all its guises, e.g. ESL/EFL, foreign language, and bilingual teaching; this means that our bilingual educators-in-the-making prepare themselves alongside foreign language and TESOL (Teaching English to Speakers of Other Languages) educators-in-the-making, and vice versa. Furthermore, we see research, theory, and practice as integrally linked and mutually informing; this means that the bilingual and language educators-in-the-making enrolled in our professional masters programmes in TESOL and Intercultural Communication prepare themselves alongside researchers-in-the-making enrolled in our doctoral programme in Educational Linguistics, and vice versa.

How does this play out in actual practice? The following vignettes from our programmes pose illustrative dilemmas confronting our bilingual, ESL/EFL, and foreign language educators-in-the-making, representative of similar dilemmas facing educators in today's postmodern and increasingly multicultural and globalised world. I begin by looking at contexts for biliteracy and the global/local dilemma; and then take up the media of biliteracy and the standard/nonstandard dilemma; the development of biliteracy and the language/content dilemma; and the content of biliteracy and the language/culture/identity dilemma. In each case, I present the dilemma in practice as experienced by our educators-in-the-making, then consider it in the light of related literature and suggest ways in which the continua model might shape a response.

\section{Contexts of Biliteracy: The Global/Local Dilemma}

Throughout the city at sites such as the Nationalities Services Centre, International House, the Jewish Educational and Vocational Service, the SHINE programme, or K-12 public school classrooms, Penn's TESOL masters students, including those who plan to be bilingual educators, carry out the required service component of their comprehensive examination, providing 30 hours of ESL instruction to recent immigrant adults, language minority children or international students. About half of these TESOL students are themselves international students who will return to their home countries to teach English in EFL settings, and for these students in particular, a recurring concern is: how can I (the teacher) apply what I am learning in this ESL teaching experience to the 
EFL context in which I will be teaching after I graduate? For that matter, how relevant is what I have learned in my courses about, for example, African-American Vernacular English or Mexican American or indigenous language education in the US to my future EFL teaching in Japan (or China or Korea)?

The call for educators, and in particular language educators, to be aware of globalisation and of the role of language education in globalisation, is being sounded by multiple voices and from myriad disciplines, of which I mention here only two. Language educator Tove Skutnabb-Kangas challenges teachers to look more into global politics and markets, and into the role of English language teaching and the diffusion-of-English paradigm in that globalisation, and to choose instead the ecology-of-language paradigm, lest the killing of linguistic and cultural diversity and the failure of education of minorities continue to be reproduced by the educational systems of the world (Skutnabb-Kangas, 1998b: 11). Unlike the diffusion-of-English paradigm which assumes a parallel between a universal/dominant language (English) and a universal/dominant economic system (capitalism) (Skutnabb-Kangas, 1998a: 3), 'the ecology-of-language paradigm involves building on linguistic diversity worldwide, promoting multilingualism and foreign language learning, and granting linguistic human rights to speakers of all languages' (Phillipson \& Skutnabb-Kangas, 1996: 429, citing Tsuda, 1994). On language ecology, see also Haugen (1972), Hornberger (2002b) and Kaplan and Baldauf (1997).

Anthropologist Kathleen Hall argues that globalisation and the consequent 'decentring of the nation-state and ... decline in the geopolitical dominance of the West have created spaces for new forms of cultural identifications and politics to emerge' (Hall, 1999: 136). Educational institutions find themselves embroiled in these emerging politics, at the heart of which are tensions between essentialist and postmodern formulations of culture and identity; traditional holistic notions of bounded, isolated entities are being challenged and replaced by an emphasis on multiple, fragmented, overlapping, contradictory, multivocal, and situationally contingent identities and cultures.

The global/local dilemma, that is, how we as bilingual educators can respond adequately and fully to both global and local pressures on our students, is an expression of the continua of biliterate context. The tensions the above authors highlight between the global/universal and the local/diverse, between bounded, isolated identities or cultures and overlapping, contradictory ones, are everpresent in the EFL/ESL, foreign, and bilingual teaching contexts that PennGSE's language educators-in-the-making experience. In every language education context, the interrelationship of dominant, standard, global English (or other dominant language) and learners' local, nonstandard or non-English (non-dominant) language practices has implications for educators' programmatic, curricular, and interactional choices. The continua of biliteracy framework provides a heuristic for educators to consider as they make their choices. Specifically, the continua frame contexts of biliteracy in terms of the interrelationships across micro-and-macro (local-and-global) levels of context, and across oral-and-literate and multilingual-and-monolingual mixes of language use; and remind educators of the need to provide space for 
the traditionally less powerful ends of those continua, i.e. for oral, multilingual interaction at the local, micro level, whether they are teaching in a bilingual classroom in Philadelphia or an EFL classroom in Korea.

\section{Media of Biliteracy: The Standard/Nonstandard Dilemma}

For TESOL teachers in EFL settings, as well as for bilingual and foreign language educators, another question which recurringly arises is: which variety of the language should I teach and use in my class? For bilingual educators in the U.S., this question might revolve around standard and nonstandard varieties of Spanish and English in the community's repertoire. For TESOL teachers in EFL settings, the question becomes one of which variety of English to promote - a 'world standard' such as American or British English, as has been traditionally hegemonic in EFL teaching, or an indigenous standard such as Singaporean English, Malaysian English, Indian English, or the like?

The standard/nonstandard dilemma, that is, how we as bilingual educators can respond adequately and fully to both the demand for standard language varieties and the prevalence and valuing of nonstandard ones, finds a helpful heuristic in the continua of biliteracy too. The continua model frames the media of biliteracy in terms of the language and literacy varieties involved, specifically the interrelationships between language structures, literacy scripts and practices, and the sequence and mix of varieties. The framework thus informs not only issues such as the coexistence of different standard and nonstandard varieties in the learners' repertoire as in the vignette above, but also questions about how to place students whose language proficiencies may reflect criss-crossed, simultaneous acquisition of multiple languages and literacies, or how to handle widely divergent writing systems, or codeswitching practices. Specifically, the continua model urges educators to give consideration to the traditionally less powerful ends of the continua, i.e. to dissimilar, divergent, nonstandard varieties and writing practices, and to codeswitching and language mixing practices, as learners draw on all the available communicative resources in their developing biliteracy.

With regard to varieties of English, Brutt-Griffler (2002) has argued that World English, far from being an entirely alien language imposed on the world by Anglo-American, Western (linguistic) imperialism, has in fact spread in large part due to the struggle against imperialism. She foregrounds the agency of non-mother-tongue English speech communities in abetting both English language spread and English language change, arguing that the two processes are intimately connected and that the proliferation of varieties of English is a necessary result of the development of World English. Bilingual, foreign, and second language speakers of English make it their own, changing the language as they spread it. Varieties of English, in this view, are not aberrations or temporary digressions from the standard to be ignored in hopes they will go away, but are instead essential to the very life of the language and therefore to be recognised and valued.

Similarly, with regard to varieties of Spanish, Valdés has consistently drawn our attention to the fact that Spanish language education for heritage speakers 
cannot be the same as for foreign language learners (Valdés, 1981, 1983). Recently, she has urged bilingual educators to be cautious in embracing twoway bilingual education, wherein English speakers learn Spanish and Spanish speakers learn English in shared classes. She suggests that the Spanish taught in such programmes may come closer to the standard taught in foreign language classes than to the nonstandard varieties the Spanish speakers bring with them to school and she urges educators to ask themselves: who will in fact be the beneficiaries of the language resources developed in the programme? (Valdés, 1997: 412-420).

With regard to codeswitching and language mixing, recent research documents the richness and complexity of codeswitching practices in multilingual classrooms around the world, and the variety of pedagogical purposes, ideological underpinnings, and ecological relationships these practices reflect. Far from dismissing these practices out of hand, these studies provide evidence that language mixing very often enables educators to contextualise and communicate academic content for multilingual learners, which would otherwise remain inaccessible due to language policies, curricula, and materials mandating instruction in languages the learners do not speak (Creese \& Martin, 2003; Heller \& Martin-Jones, 2001; Martin-Jones \& Heller, 1996).

Beyond nonstandard and mixed uses of language, the continua model also urges educators to make space for the multiple communicative media available in today's world. The New London Group (1996; Cope \& Kalantzis, 2000) uses the term multiliteracies to refer to the multiplicity of communications channels and media in our changing world (and secondarily to the increasing saliency of cultural and linguistic diversity); the concept of multiliteracies in this sense extends literacy beyond reading and writing to other communicative modes, such as the visual, audio, spatial, and behavioural.

The New London Group's notion of multiliteracies is echoed in Street's recent call for language educators to pay more attention to a broader notion of languages and literacies. Street (1999) points out that the New Work Order, with its emphasis on asset building and market share and on workplace behaviours like flexibility, adaptation to change, and collaboration (Gee et al., 1996), implies an analogous New Communicative Order (cf. Kress \& van Leeuwen, 1996), in which management skills, general communication skills, computer literacy, and interpretation of icons, signs, and visual images such as those on the internet are as much in demand as traditional reading and writing literacy skills (or more so). He draws on the work of Bakhtin (1981) (heteroglossia), Halliday (1985) (systemic linguistics), Hymes (1964) (ethnography of communication), and Kress (1997) (social semiotics), for a theoretical framework for analysing, understanding and teaching this communicative competence broadly defined, i.e. 'knowing when and how to use resources from different channels' (Street, 1999: 3).

Where Skutnabb-Kangas refers to global/local tensions in terms of diffusion-of-English and ecology-of-language paradigms, and Hall in terms of globalising forces and the emerging politics of culture and identity, Street borrows Bakhtin's metaphor of the centripetal and centrifugal forces of heteroglossia to urge that 'as centripetal forces [e.g. government prescriptions] and the pressure to take language literally become ever more powerful' (Street, 
1999: 23), educators - and in particular language educators - need to acknowledge centrifugal forces [new communicative practices] as well and to reconceptualise the 'role of language in education in terms of this wider framework for language, literacy, and communication' (Street, 1999: 16). He cites examples of these new communicative practices such as the mixed modalities evident in the use of text and image in a water quality slide intended to help people in South Africa recognise when water is safe to drink, or in American teenagers' use of beepers to pass messages that are a mix of Morse Code and logographic principles which also frequently draw on historical and cultural associations (e.g. the numbers 66 used to mean 'let's hit the road', drawing on cultural knowledge of the TV series Route 66); these examples extend the standard/nonstandard dilemma beyond language varieties per se to the whole range of visual, audio, spatial, and behavioural semiotic modes and modalities available for communication in today's world. For the bilingual educator, then, the continua model offers an awareness of the many and varied codes and channels available as communicative resources and a heuristic for decision-making as to when and how to use these resources.

\section{Development of Biliteracy: The Language/Content Dilemma}

A small core group of teachers and administrators at Potter Thomas Bilingual Elementary School in North Philadelphia's Puerto Rican community are simultaneously implementing a new maths curriculum and piloting portfolio assessment as an alternative to standardised testing. As Penn Educational Linguistics doctoral student Melisa Cahnmann and I work with them during a 3-day summer workshop on issues of mathematics, language, and portfolio assessment with bilingual and bidialectal urban youth, we attempt to address the question which resurfaces constantly for these teachers: when should I (the teacher) be evaluating my students for their language and when for their maths knowledge, and how can I keep the two separate?

Cochran-Smith and Lytle, long-time PennGSE colleagues and founders of the Practitioner Enquiry strand of PennGSE's annual Ethnography in Education Research Forum (Hornberger, 2002a), explore three conceptions of teacher learning in relation to university-based research: the knowledge-forpractice conception, which assumes that university-based researchers generate knowledge for teachers to use in order to improve their practice; the knowledge-in-practice conception, in which teachers are assumed to learn from the opportunity to probe knowledge embedded in the work of expert teachers; and the knowledge-of-practice conception, in which it is assumed that the knowledge teachers need to teach well is generated when teachers treat their own classrooms and schools as sites for intentional investigation at the same time that they treat the knowledge and theory produced by others as generative material for interrogation and interpretation' (Cochran-Smith \& Lytle, 1999: 250).

In elaborating on the knowledge-of-practice conception of teacher learning, they emphasise the importance of the enquiry community and of an enquiry stance as modus operandi (Cochran-Smith \& Lytle, 1999: 289). Among the 
examples of enquiry communities they mention are the National Writing Project, where knowledge about the teaching of writing, language, and literacy is constructed collaboratively, teacher to teacher, in local, regional, and national institutes and on-line networks over time; the locally based Philadelphia Teachers' Learning Cooperative, where teachers set out 'to improve their knowledge and practice by documenting children's learning in school contexts, uncovering and clarifying their implicit assumptions about teaching, learning and schooling, and solving a variety of school-based educational problems', also over time (Cochran-Smith \& Lytle, 1999: 285-286); and the Santa Barbara Classroom Discourse Group, another locally based ongoing collaborative community of teachers, researchers, and graduate students 'who are concerned with understanding how everyday life in classrooms is constructed by members through their interactions, verbal and other, and how these constructions influence what students have opportunities to access, accomplish, and thus, "learn" in schools' (Green \& Dixon, 1993: 231). Importantly, these enquiry communities engage in these processes over time, on the order of years and decades, not weeks or months.

The common work of these practitioner enquiry communities is 'to generate local knowledge, envision and theorise their practice, and interpret and interrogate the theory and research of others', what Cochran-Smith and Lytle call 'taking an enquiry stance' (1999: 289). The metaphor 'enquiry as stance' is intended to capture 'the ways we stand, the ways we see, and the lenses we see through' (1999: 288); it is a stance which intentionally stands against the epistemological dualism of formal knowledge-practical knowledge and which regards both knowledge generation and knowledge use as inherently problematic.

As Cahnmann and I, two university-based researchers, grapple together with Potter Thomas staff over guiding and assessing bilingual and bidialectal learners' developing maths understandings, we together enact an incipient enquiry community such as described above, where knowledge emerges in the practice of education, here in the form of a persistent question about how teachers should evaluate their biliterate learners' language and academic development (Cahnmann \& Hornberger, 2000). Later, in her own dissertation research, Cahnmann uses what she calls the core aspects of the continua of biliteracy - monolingual-bilingual norms, oralcy-literacy, and micro-macro to understand the struggle and contradiction involved in one bilingual teacher's assessment and correction of students' oral and written productions; and concludes that the answer to whether a teacher should or should not correct a student's work is better understood as a continuum of complex and multifaceted considerations (Cahnmann, 2003).

In seeking answers to the language/content dilemma, that is, how we as bilingual educators can respond adequately and fully to the demands of teaching and evaluating both language and content, the continua of biliteracy model again offers a useful heuristic, framing learners' developing languages and literacies in terms of the interconnectedness of oral-written, receptiveproductive, and L1-L2 dimensions, and linking those not only to context and media, but to content as well. Specifically, the continua model reminds us that biliteracy learning may proceed in any direction along the three intersecting 
continua and that it may do so by backtracking, spurting, or criss-crossing just as readily as by steadily progressing in linear fashion; and further that there is an infinite potential for transfer of skills across any of the three continua, but, by the same token, understanding or predicting transfer is elusive if not impossible, precisely because the three continua are interrelated and furthermore nested within all the other continua. This means that educators' evaluation of learners' work must also be holistic across the continua, always taking into account that an ungrammatical expression of accurate content, or a grammatically correct expression of inaccurate content, may be just as much a sign of learning as a grammatically correct expression of accurate content. It is here that the value of the enquiry community and enquiry stance come to the fore as educators struggle to work out the specifics of such holistic evaluations in their day-to-day practice.

\section{Content of Biliteracy: The Language/Culture/Identity Dilemma}

A number of Penn Intercultural Communications masters students and Educational Linguistics doctoral students are employed as foreign language instructors at various Penn departments, such as Romance Languages, Asian and Middle Eastern Studies, and the Penn Language Centre. Several teach in the Lauder Institute of Management and International Studies, which offers a combined liberal arts and business degree with an international focus, at both the bachelor's and master's level. As our students teach Spanish, French, Chinese, Japanese, or other languages to prospective business people, they often confront this challenge: how can I as teacher and representative of my native language and culture counter the lack of respect for or genuine interest in other worldviews which I sometimes find in my students? To what degree is an understanding of the new culture a necessary part of learning a new language, and to the degree that it is, which 'culture' should be taught?

'In EFL classrooms', Duff and Uchida write, 'issues of sociocultural identity and representation are very important' (Duff \& Uchida, 1997: 452). Like Skutnabb-Kangas above, as well as Tollefson (1991), Pennycook (1994), Hornberger and Ricento (1996) and others, they note that 'the English language teaching industry is not culturally, politically, socially, or economically neutral' and EFL in particular 'plays a powerful role in the construction of roles, relations, and identities among teachers and students' (Duff \& Uchida, 1997: 452). Furthermore, they point out that social and cultural aspects of other groups, particularly those associated with the target language, are often discussed in foreign language classes and that 'teachers' or students' identities and beliefs related to gender roles, nationality, ethnicity, teaching methods, and language use [may] conflict with those of colleagues, students, professional publications, popular media, or local cultures' (Duff \& Uchida, 1997: 452). They ask: how do teachers negotiate these issues? how do they reconcile their own sense of identity with 'national stereotypes of their own and others' linguistic and cultural values? how do they negotiate the curriculum in terms of its cultural content?' (Duff \& Uchida, 1997: 453).

In an in-depth study of four EFL teachers in Japan, they found that teachers' 
perceptions of their own sociocultural identities were 'deeply rooted in their personal histories, based on past educational, professional and (cross-)cultural experiences', but that these same identities 'were also subject to constant negotiation due to changing contextual elements, such as the classroom/ institutional culture, instructional materials, and reactions from students and colleagues' (Duff \& Uchida, 1997: 460). Themes of complexity and dynamic negotiation predominate in their description of teachers as 'cultural workers' (Giroux, 1992) in their EFL classrooms.

Similarly, but in a different context - that of urban bilingual educators in Philadelphia, Varghese argues that becoming a bilingual educator is primarily a process of negotiating professional identities, rather than simply one of acquiring skills and knowledge per se. Her study explores how the professional identities of a group of bilingual Latino teachers-in-the-making are formed, interpreted, and enacted and how national and local discourses influence that identity formation and enactment (Varghese, 2000: vi). Particularly striking in her findings is the uncovering of a ubiquitous but implicit assumption that, given the (increasingly) political and controversial nature of bilingual education in the United States, bilingual educators need to be advocates and agents for change (Varghese, 2000: 1). Like Cummins (1996), she sees the negotiation of identities as a potential but not automatic tool for the empowerment of bilingual educators and their students, one which is mediated by the teachers' understandings of their local settings and their personal histories; as Varghese shows, although all the teachers-in-the-making in her study had a sense of the advocacy/change agency role for bilingual educators, only some of them enacted it, while others avoided it by focusing exclusively on their classroom practice or by leaving the profession altogether (Varghese, 2000: 2).

In another case of urban bilingual education, that of multilingual learners in England, Leung et al. (1997) also emphasise the making, remaking, and negotiating of cultural identities. These learners, they argue, 'actively construct their own patterns of language use, ethnicity, and social identity', often in 'strong contradiction to the fixed patterns and the reified ethnicities attributed' to them (Leung et al., 1997: 544). In contexts like these, they suggest, it makes more sense for language educators to think of learners' language proficiency in terms of language expertise, affiliation, and inheritance, rather than native speaker, non-native speaker or mother tongue categories. In these terms, language expertise refers to how proficient they are, while language affiliation refers to the 'attachment or identification [they] may feel for a language whether or not they nominally belong to the social group customarily associated with it' and language inheritance to the 'ways in which individuals can be born into a language tradition ... whether or not they claim expertise in or affiliation to [it]' (Leung et al., 1997: 555).

The language/culture/identity dilemma, that is, how we as bilingual educators can respond adequately and fully to dynamic negotiation of cultures and identities and of overlapping language affiliations not necessarily linked to expertise or inheritance, finds resonance in the continua of biliteracy heuristic which frames the content of biliteracy in terms of continuities - from minority to majority representations, vernacular to literary expressions, and con- 
textualised as well as traditional academic decontextualised forms (see also Cummins, 2003). Skilton-Sylvester, in her study of literacy, identity, and educational policy among Cambodian women and girls in Philadelphia, argues that these content dimensions allow for looking not only at where languages and literacies are used and learned (context), what aspects are used and learned (media), and how they are used and learned (development), but also the kinds of meanings expressed in particular biliterate contexts, through specific biliterate media, and during particular moments of biliterate development. Whereas the media continua focus on the forms literacies take, the content continua focus on the meanings those forms express. In particular, she argues for the importance of including minority, vernacular and contextualised whole language texts in bilingual learners' literacy experiences (Skilton-Sylvester, 1997). These considerations are essential for bilingual educators as they negotiate issues of cultural stereotyping, intercultural respect, and conflicting or overlapping cultural traditions and particularities, such as those highlighted in the above vignette.

\section{Concluding Comments}

Bilingual educators are simultaneously researchers, teachers, and language planners. The continua of biliteracy model can serve as heuristic as these educators daily face dilemmas instantiated in programmatic, curricular, and interactional choices in their classrooms and schools, in the course of their practice. As we have seen above, the continua of biliteracy framework as heuristic encourages bilingual educators, in their role as teachers, to approach biliterate learners' developing communicative competence in socioculturally and sociopolitically contextualised, locally and multiply inclusive, enquiry-based, and dynamically negotiated ways. As researchers, bilingual educators (and all language educators) need to have opportunities to reflect critically on the contexts and content of their teaching; and to uncover the communicative repertoires (media) that students bring to school and that can serve as resources for their language and literacy development.

As language planners, bilingual educators have a particularly important role to play. Skilton-Sylvester reminds us that 'looking at the ways teachers create classroom policies of their own while accepting and challenging the policies that are handed down to them is a useful and important endeavour in working toward more equitable educational policies and practices for linguistically diverse students' (Skilton-Sylvester, 2003: 170). She cites Ricento and Hornberger (1996: 408) on the permeability of policy across its multiple layers from macro to micro and the greater likelihood of change coming from the bottom-up than from the top-down. Schwinge provides an example of just this: using the continua model to analyse curricular modifications made by two elementary school teachers working with Latino biliterate learners, she shows that while there is a growing trend in American education for schools to adopt standardised curricula like the Success for All reading programme, some bilingual education teachers act as bottom-up language and literacy planners by adapting and elaborating on the suggested activities and the content of the mandated programmes to better enable their students to become bilingual, biliterate, and bicultural (Schwinge, 2003). As English-only policies 
and monolingual language ideologies continue to exert their sway both nationally and internationally, we need bilingual educators to be conscious advocates for the language rights and resources of language minority students and speakers of endangered, indigenous, immigrant, and ethnic languages, wherever they may be.

\section{Correspondence}

Correspondence should be directed to Nancy H. Hornberger, Graduate School of Education, University of Pennsylvania, 3700 Walnut Street, Philadelphia, PA 19104-6216, USA (nancyh@gse.upenn.edu).

\section{Notes}

1. An early version of this paper was presented as a plenary at the international conference on Research and Practice in Language Teacher Education: Voices from the Field, on 1 May 1999, in Minneapolis, Minnesota.

2. Portions of this section, including the figures, were first published in Hornberger and Skilton-Sylvester (2000) and are reprinted here with permission of Multilingual Matters Publishers, Clevedon, UK.

3. The programmes in Educational Linguistics, then and now, encompass the Ph.D. specialisation in Educational Linguistics begun in 1976 and master's specialisations in Teaching English to Speakers of Other Languages (TESOL, also dating from 1976) and Intercultural Communication (launched in 1978). I have been affiliated with these programmes since 1985, and have directed them for much of that time. See Hornberger $(2001 \mathrm{a}, \mathrm{b})$ for a more complete account of the Educational Linguistics programmes. By intention, a number of the scholars cited here for illustrative purposes are graduates (or current students) of the Educational Linguistics PhD program whose own research focused on bilingual education and/or biliteracy: Cahnmann, Creese, Schwinge, Skilton-Sylvester, and Varghese.

4. My thanks to an anonymous reviewer for bringing out this point.

\section{References}

Bakhtin, M. (1981) The Dialogic Imagination. Austin: University of Texas Press.

Brutt-Griffler, J. (2002) World English: A Study of its Development. Clevedon: Multilingual Matters.

Cahnmann, M. (2003) To correct or not to correct bilingual students' errors is a question of continua-ing reimagination. In N.H. Hornberger (ed.) Continua of Biliteracy: An Ecological Framework for Educational Policy, Research, and Practice in Multilingual Settings (pp. 187-204). Clevedon: Multilingual Matters.

Cahnmann, M. and Hornberger, N.H. (2000) Understanding what counts: Issues of language, culture, and power in mathematics instruction and assessment. Educators for Urban Minorities 1 (2), 39-49.

Cochran-Smith, M. and Lytle, S. (1999) Relationships of knowledge and practice: Teacher learning in communities. Review of Research in Education, 24, 249-305.

Cope, B. and Kalantzis, M. (eds) (2000) Multiliteracies: Literacy Learning and the Design of Social Futures. London: Routledge.

Creese, A. and Martin, P. (eds) (2003) Multilingual classroom ecologies: Interrelationships, interactions, and ideologies. International Journal of Bilingual Education and Bilingualism (Entire issue).

Cummins, J. (1996) Negotiating Identities: Education for Empowerment in a Diverse Society. Ontario, CA: California Association for Bilingual Education.

Cummins, J. (2003) Foreword. In N.H. Hornberger (ed.) Continua of Biliteracy: An Ecological Framework for Educational Policy, Research, and Practice in Multilingual Settings (pp. vii-xi). Clevedon: Multilingual Matters. 
Duff, P.A. and Uchida, Y. (1997) The negotiation of teachers' sociocultural identities and practices in postsecondary EFL classrooms. TESOL Quarterly 31 (3), 451-486.

Gee, J.P., Hull, G. and Lankshear, C. (1996) The New Work Order: Behind the Language of the New Capitalism. Boulder, Colorado: Westview Press.

Giroux, H.A. (1992) Border Crossings: Cultural Workers and the Politics of Education. London: Routledge.

Green, J.L. and Dixon, C.N. (1993) Talking knowledge into being: Discursive and social practices in classrooms. Linguistics and Education 5 (3\&4), 231-239.

Hall, K. (1999) Understanding educational processes in an era of globalisation. In E.C. Lagemann and L.S. Shulman (eds) Issues in Education Research (pp. 121-156). San Francisco: Jossey-Bass Publishers.

Halliday, M.A.K. (1985) An Introduction to Functional Grammar. Baltimore, MD: Edward Arnold.

Haugen, E. (1972) The Ecology of Language. Stanford, CA: Stanford University Press.

Heller, M. and Martin-Jones, M. (eds) (2001) Voices of Authority: Education and Linguistic Difference. Norwood, NJ: Ablex.

Hornberger, N.H. (1989) Continua of biliteracy. Review of Educational Research 59 (3), 271-296.

Hornberger, N.H. (1990) Creating successful learning contexts for bilingual literacy. Teachers College Record 92 (2), 212-229.

Hornberger, N.H. (2001a) Educational linguistics as a field: A view from Penn's programme as it approaches its 25th anniversary. In R.L. Cooper, E. Shohamy and J. Walters (eds) New Perspectives and Issues in Educational Language Policy: A Festschrift for Bernard Dov Spolsky (pp. 271-296). Philadelphia: John Benjamins.

Hornberger, N.H. (2001b) Educational linguistics as a field: A view from Penn's programme on the occasion of its 25th anniversary. Working Papers in Educational Linguistics 17 (1-2), 1-26.

Hornberger, N.H. (2002a) Introduction. PennGSE Perspectives on Urban Education (2), at www.urbanedjournal.org.

Hornberger, N.H. (2002b) Multilingual language policies and the continua of biliteracy: An ecological approach. Language Policy 1 (1), 27-51.

Hornberger, N.H. and Ricento, T.K. (1996) Language planning and policy and the English language teaching profession. TESOL Quarterly 30 (3), entire issue.

Hornberger, N.H. and Skilton-Sylvester, E. (2000) Revisiting the continua of biliteracy: International and critical perspectives. Language and Education: An International Journal 14 (2), 96-122.

Hymes, D.H. (1972) On communicative competence. In J. B. Pride and J. Holmes (eds) Sociolinguistics: Selected Readings (pp. 269-293). Harmondsworth: Penguin Books.

Hymes, D.H. (1964) Introduction: Toward ethnographics of communication. American Anthropologist 66 (6), 1-34.

Kaplan, R.B. and Baldauf, R.B. (1997) Language Planning: From Practice to Theory. Clevedon, UK: Multilingual Matters.

Kress, G. (1997) Before Writing: Rethinking the Paths to Literacy London: Routledge.

Kress, G. and Leeuwen, T.V. (1996) Reading Images: The Grammar of Visual Design. London: Routledge.

Leung, C., Harris, R. and Rampton, B. (1997) The idealised native speaker, reified ethnicities, and classroom realities. TESOL Quarterly 31 (3), 543-560.

Martin-Jones, M. and Heller, M. (1996) Introduction to the special issues on education in multilingual settings: Discourse, identities, and power. Linguistics and Education 8 (1), 3-16.

New London Group (1996) A pedagogy of multiliteracies: Designing social futures. Harvard Educational Review 66 (1), 60-92.

Pennycook, A. (1994) The Cultural Politics of English as an International Language. London: Longman.

Phillipson, R. and Skutnabb-Kangas, T. (1996) English only worldwide or language ecology? TESOL Quarterly 30 (3), 429-452. 
Ricento, T.K. and Hornberger, N.H. (1996) Unpeeling the onion: Language planning and policy and the ELT professional. TESOL Quarterly 30 (3), 401-428.

Schwinge, D. (2003) Enabling biliteracy: Using the continua of biliteracy to analyse curricular adaptations and elaborations. In N.H. Hornberger (ed.) Continua of Biliteracy: An Ecological Framework for Educational Policy, Research, and Practice in Multilingual Settings (pp. 248-265). Clevedon: Multilingual Matters.

Skilton-Sylvester, E. (1997) Inside, outside, and in-between: Identities, literacies, and educational policies in the lives of Cambodian women and girls in Philadelphia. Unpublished Ph.D., University of Pennsylvania, Philadelphia.

Skilton-Sylvester, E. (2003) Legal discourse and decisions, teacher policymaking and the multilingual classroom: Constraining and supporting Khmer/English biliteracy in the United States. International Journal of Bilingual Education and Bilingualism $6(3 \& 4), 168-184$.

Skutnabb-Kangas, T. (1998a) Linguistic diversity, human rights and the 'free' market. In M. Kontra, R. Phillipson, T. Skutnabb-Kangas and T. Várady (eds) Approaches to Linguistic Human Rights. Budapest: Central European University Press.

Skutnabb-Kangas, T. (1998b) The politics of (ESL in) multilingual education: Languages, culture, power and liberation. Unpublished manuscript.

Street, B. (1999) New literacies in theory and practice: What are the implications for language in education? Linguistics and Education 10 (1), 1-24.

Tollefson, J.W. (1991) Planning Language, Planning Inequality: Language Policy in the Community. London: Longman.

Tsuda, Y. (1994) The diffusion of English: Its impact on culture and communication. Keio Communication Review 16, 49-61.

Valdés, G. (1981) Pedagogical implications of teaching Spanish to the Spanish-speaking in the United States. In G. Valdés, A.G. Lozano and R. García-Moya (eds) Teaching Spanish to the Hispanic Bilingual: Issues, Aims, and Methods (pp. 3-29). New York: Teachers College Press.

Valdés, G. (1983) Planning for biliteracy. In L. Elías-Olivares (ed.) Spanish in the US Setting: Beyond the Southwest (pp. 259-262). National Clearinghouse for Bilingual Education.

Valdés, G. (1997) Dual-language immersion programs: A cautionary note concerning the education of language-minority students. Harvard Educational Review 67 (3), 391-429.

Varghese, M.M. (2000) Bilingual teachers-in-the-making: Advocates, classroom teachers, and transients. Unpublished PhD thesis, University of Pennsylvania, Philadelphia. 